\title{
ЕЛЕКТРОННИ ПРАВИТЕЛСТВА В СТРАНИТЕ ОТ ЧЕРНОМОРСКИЯ РЕГИОН - ФАКТОР ЗА ПРОЗРАЧНОСТ И ОПТИМАЛНА КОМУНИКАЦИЯ
}

\author{
Павлина Лозанова \\ E-GOVERNMENTS IN THE COUNTRIES OF THE BLACK SEA REGION - A \\ FACTOR FOR TRANSPARENCY AND BETTER COMMUNICATION \\ Pavlina Lozanova
}

\begin{abstract}
The progressive development of societies and economies is marked increasingly by the growing role of digital knowledge and information technologies. With the creation of a global information space, the digitization of society and the wider use of internet technologies through traditional and electronic media, the development of e-Government is becoming increasingly popular and functional. Nowadays, the organization of public administration on the basis of electronic means of processing, transmitting and disseminating information, providing services to public authorities, businesses and citizens electronically, the information interaction of public authorities and society using information telecommunications technologies, and ensuring free access for citizens to the relevant state information, are the main components of a comprehensive transformation of governance into the e-government format.
\end{abstract}

Key words: e-governments, Black Sea Region, digitalization

DOI: https://doi.org/10.46687/PHGH5131

Съществуват различни определения за обхвата на Черноморския регион. Този факт по същество е показателен за нехомогенността на региона по отношение най-вече на исторически, етнически, геополитически и икономически фактори. За целите на настоящата публикация ще бъде използвано приетото през 2007 г. становище от Европейската Комисия ${ }^{1}$. Според него Черноморският регион включва, освен страните, които имат непосредствен излаз на Черно море България, Грузия, Румъния, Русия, Турция и Украйна - така и тези, които и без такъв са повлияни от него поради исторически причини, географско разположение и близки връзки с горните страни. Последната група включва Гърция, Република Молдова и останалите две южнокавказки

\footnotetext{
${ }^{1}$ European Commission. 2007. Communication from the Commission to the Council and the European Parliament. Black Sea synergy: A new regional cooperation initiative. COM (2007) 160 final. Brussels: EC.
} 


\section{Годишник на ФХH, XXXII A}

държави Армения и Азербайджан. Различните разбирания за обхвата на региона намират израз и в разнообразните конфигурации на регионално сьтрудничество. В най-значимото регионално обединение например Организацията за Черноморско икономическо сътрудничество (ОЧИС), наред с вече изброените десет държави, страни членки са също Албания, Сърбия и Северна Македония (пълноправен член от ноември 2020 г.).

Изпълнението на всеобхватни програми за електронно управление в страните от Черноморския регион продължава вече десетилетие и към настоящия момент са постигнати осезаеми успехи. Особено след появата на Covid-19 пандемията въпросът за ускоряване на процесите на дигитализация в дейността на правителствата става все по-актуален. Изпълнението на спешни задачи при трудни пандемични условия, осигуряването на своевременно вземане на решения в извънредни ситуации и възможно най-бързото предоставяне на информация на населението изискват новаторски подходи при използването на ефективни цифрови средства за комуникация, както и подобряване на стандартите за обмен на данни, по-ефективно използване на интернет, електронни медии и социални мрежи.

Дигитализацията и новите информационни технологии са найефективният двигател на развитието на съвременното общество. Около 5 трилиона щатски долари се инвестират в световен мащаб за развитието на цифровите технологии, а тази цифра нараства с всяка следваща година. Цифровите технологии присъстват в живота на съвременния човек, в професионалните му дейности и в свободното му време и биват важен компонент на комуникацията. Политиката, както и други обществени сфери, се разглеждат и през призмата на дигитализацията. Цифровите платформи постепенно се интегрират в политическите процеси, политическата комуникация и публичната администрация. Цифровите технологии се използват широко в политическите процеси и в работата на правителствата и парламентите: електронно гласуване, електронна демокрация, електронно участие, онлайн кампании, електронен парламент и др.

Благодарение на научно-техническия прогрес и въвеждането на нови информационни технологии се стимулира модернизирането на икономическата, образователната, културната и политическата среда. Електронното управление като качествено нова форма на управление, присъща на информационното общество, се счита за лост за активното използване на интернет технологиите с цел регулиране на политическата сфера. 


\section{Павлина Лозанова. Електронни правителства...}

Реализирането на електронното управление и в частност на електронното правителство не е просто усъвършенстване на конвенционалните управленски технологии. Неговите цели са не само подобряване на управлението, облекчаване работата на персонала, икономии на средства и др. Това е нова философия и парадигма на управление. Международни организации като Организацията на обединените нации $(\mathrm{OOH})$ и Организацията за икономическо сътрудничество и развитие (ОИСР) дават различни определения на термина „електронно управление“. ОИСР определя електронното управление като прилагане на информационни и комуникационни технологии (ИКТ), по-специално интернет технологии, като инструмент за подобряване на ефективността на управлението. ООН го разглежда като управление, което използва ИКТ за вътрешна трансформация и външни отношения. Крайната цел на електронното управление е да осигури ефективна публична администрация, т. е. да постави правителството във възможно най-удобна позиция от държавна гледна точка. Нейната цел е да осигури рамка за успешния преход към ясна, прозрачна и ефективна публична администрация.

Електронното управление е система за управление на документи, основана на автоматизацията на целия набор от процеси на управление в цялата страна и целяща значително подобряване на ефективността на публичната администрация и намаляване на разходите за социални комуникации за всеки член на обществото. Задачите на електронното управление включват: оптимизиране на предоставянето на държавни услуги на населението и бизнеса; подкрепа и разширяване на възможностите за самообслужване за гражданите; растеж на технологичната осведоменост и квалификация на гражданите; увеличаване на участието на всички гласоподаватели в процесите на управление на страната; намаляване на въздействието на фактора географско местоположение. Същността на електронното управление е да трансформира публичната администрация и да гарантира иновативни вътрешни и външни връзки чрез електронни технологии. Електронното правителство включва не само технически иновации, но и реформа на правителството, съсредоточена върху нуждите на публичния сектор, от една страна, и гражданите и предприятията, от друга, както и оптимизиране на методите на взаимодействие между публичния и частния сектор.

Основните цели на електронното управление са да се постигне максимална прозрачност на дейностите на всички структури на 


\section{Годишник на ФХH, XXXII A}

публичната администрация, като на гражданите се предоставя възможност да упражняват контрол върху изпълнението и приемането на политически решения на различни равнища. Електронното правителство гарантира предоставянето на информация и установен набор от обществени услуги на гражданите, бизнеса, другите клонове на държавна власт и правителствени служители, в които контактьт между държавата и заявителя е сведен до минимум за сметка на по-широкото използване на информационните технологии.

Би могло да бъде възприето следното определение за електронно управление: „съвкупност от стратегически и тактически мерки, политики и технологични решения, определящи рамката за развитие и функциониране на „информационното общество”. Както е известно, еуправлението е по-широко понятие от електронното правителство, което от своя страна се дефинира като „система, съчетаваща използването на информационните и комуникационните технологии от държавната администрация с организационни изменения и новопридобити умения, водещи до подобряването на обществените услуги и демократичния процес"2.

В исторически план необходимостта за въвеждане на електронно управление е силно изразена във финалните документи на Световната среща на върха по въпросите на информационното общество (Женева 2003 г. и Тунис 2005 г.). В Женевския план за действие за електронно управление се предвижда изпълнението на стратегия за електронно управление, като се акцентира върху: ролята на органите за обществено управление и на всички заинтересовани страни в насърчаването на ИКТ за развитие; информационна и комуникационна инфраструктура; достьп до информация и знания; изграждане на капацитет; изграждане на доверие и сигурност при използването на ИКТ; изграждане на ИКТ приложения: е-правителство; е-бизнес; е-обучение; е-здравеопазване; езаетост; е-среда; е-селското стопанство; е-наука.

Електронното управление предоставя следните основни модули на взаимодействие: между държавата и гражданите (G2C, Government to Citizen); между държавата и бизнеса (G2B, Government to Business); между различните клонове на управлението (G2G, Government to

${ }^{2}$ Communication from the Commission to the Council, the European Parliament and Social Committee of the Regions (COM (2003) 567 final). 


\section{Павлина Лозанова. Електронни правителства...}

government); между държавата и държавни служители (G2E, Government to Employees).

„Правителство към правителство“ (G2G) включва споделяне на данни и електронен обмен между правителствените участници. Това включва както вътрешно- и междуведомствен обмен на национално равнище, така и обмен между националното и местното равнище. „Правителство към бизнес“ (G2B) включва специфични за бизнеса сделки (например плащания, продажба и закупуване на стоки и услуги), както и предоставяне на услуги, фокусирани върху бизнеса. „Правителство към потребител/гражданин“ (G2C) включва инициативи, предназначени да улеснят взаимодействието на хората с правителството като потребители на обществени услуги и като граждани. Това включва взаимодействия, свързани с доставката на обществени услуги, както и с участие в процеса на консултации и вземане на решения.

Глобалният индекс за развитие на електронното правителство на OOH (The UN Global E-Government Development Index) е всеобхватен показател, който оценява готовността и възможностите на националните правителствени агенции да използват информационни и комуникационни технологии за предоставяне на обществени услуги на гражданите. Той е периодичен индекс, чиято цел е да предостави обстойна и точна оценка за степента на развитие на електронното правителство в различните страни членки на ООН. Проучването и измерването на развитието на електронното правителство се провежда от Департамента по икономически и социални въпроси на Организацията на обединените нации (ООН). Първото издание е от 2003 г., като в следващите години индексът се публикува всяка година. След 2008 г. започва да излиза веднъж на две години. Методологическата рамка за събиране и оценка на данните от изследването на развитието на електронното правителство се основава на цялостен поглед върху електронното правителство, който включва три важни измерения, които позволяват на хората да се възползват от онлайн услугите и информацията: адекватност на телекомуникационната инфраструктура, способност на човешките ресурси да използват ИКТ и наличие на онлайн услуги. Измерва се също и доколко са ефективни държавните институции във включването на обществото в процеса на формиране на политики. 


\begin{tabular}{|l|c|c|c|c|}
\hline & $\begin{array}{c}\text { Позиция } \\
2014 \text { г. }\end{array}$ & $\begin{array}{c}\text { Позиция } \\
2020 \text { г. }\end{array}$ & $\begin{array}{c}\text { Индексът за } \\
\text { развитие на } \\
\text { електронното } \\
\text { правителство } \\
\text { (EGDI) }\end{array}$ & $\begin{array}{c}\text { Промяна } \\
2020 \text { г. } \\
\text { спрямо } \\
2014 \text { г. }\end{array}$ \\
\hline $\begin{array}{l}\text { Руска } \\
\text { федерация }\end{array}$ & 27 & 36 & 0.82 & -9 \\
\hline Гьрция & 34 & 42 & 0.81 & -8 \\
\hline България & 73 & 44 & 0.79 & 29 \\
\hline Турция & 71 & 53 & 0.77 & 18 \\
\hline Румъния & 64 & 55 & 0.76 & 9 \\
\hline Сърбия & 69 & 58 & 0.74 & 11 \\
\hline Албания & 84 & 59 & 0.73 & 25 \\
\hline Грузия & 56 & 65 & 0.71 & -9 \\
\hline Армения & 61 & 68 & 0.71 & -7 \\
\hline Украйна & 87 & 69 & 0.71 & 18 \\
\hline Азербайджан & 68 & 70 & 0.71 & -2 \\
\hline $\begin{array}{l}\text { Република } \\
\text { Молдова }\end{array}$ & 66 & 79 & 0.68 & -13 \\
\hline
\end{tabular}

Според данните в доклада за 2020 г. страната ни се позиционира на 44-то място сред 193 държави по отношение на Индекса за развитие на електронното правителство и за първи път влиза в категорията много висока степен на развитие на електронното управление заедно със страните от Черноморския регион. Резултатите показват, че страната ни, заедно с останалите в тази категория, демонстрира последователност и напредък в разработването на стратегически документи в областта на електронното управление и в координацията и предоставянето на електронни услуги.

Правителственият портал е ключов компонент на електронното управление по отношение на осигуряването на лесен достъп на гражданите и предприятията до информация и обществени услуги. Основната идея, свързана със създаването на правителствен портал, е обобщаването на информацията и услугите, които се предоставят от 


\section{Павлина Лозанова. Електронни правителства...}

различни отдели, и създаване на единна точка на достъп до всяка информация и услуга. Този портал служи като мощен инструмент за избор и интегриране на значително количество информация, с която разполага публичната администрация. С развитието на електронното управление в технологията на мобилните и социалните медии този портал се преврьща в място, където правителството активно поддържа обратна връзка с гражданите и се консултира с всички сегменти на обществото, за да взема решения, които са в интерес на всички.

В процеса на подготовка на дейностите на електронното управление разработването на подходящо законодателство и регулаторна рамка е предпоставка за успешното му функциониране, тъй като работата на публичната администрация следва да се извършва стриктно въз основа на законодателството. За да се създаде институционална рамка за електронното управление, е необходимо да се изменят законите и правните актове, регламентиращи въпросите, свързани с гражданското право.

Повишената дигитализация на правителствените дейности допринася за по-голяма прозрачност и откритост. Иновативните подходи в работата на правителствените структури подобряват механизмите за наблюдение и укрепване на демократичната система на управление и създават необходимите условия за подобряване на ефективността на законодателния процес. В тази връзка е необходимо да се осигури преход към по-прозрачна и ефективна публична администрация, което изисква добре изградени стратегии, дългосрочни инвестиции и използване на информационни и комуникационни технологии (ИКТ) по най-ефикасен и устойчив начин. Успоредно с това е необходимо да се гарантира устойчивостта на техническата инфраструктура, включително далекосъобщително оборудване, софтуер, специални приложения и услуги за информационна сигурност. Дьржавите по света, включително държавите членки на ЧИС, въвеждат различни информационни и комуникационни платформи за укрепване на механизма за отчетност, тъй като участието на гражданите в оценката на резултатите на демократичните институции и качеството на демократичните процеси е изключително важно в съвременния свят.

В ерата на информационното общество и в условията на широко въвеждане на нови информационни технологии, наред с новите възможности, възникват нови рискове с възможни отрицателни последици, свързани със защитата на големите информационни масиви. В информационното и комуникационно пространство на новите 


\section{Годишник на ФХH, XXXII A}

технологии е необходимо да се установят строги правила за работа с лични данни, като се вземат предвид интересите на обществената безопасност. В тази връзка е необходимо да се обърне специално внимание на осигуряването на информационна безопасност и сигурност.

Според доклада от 2020 г. на Интерпарламентарния съюз относно електронните парламенти пандемията Covid-19 води до необходимостта да се отдаде по-голямо значение на използването на информационни и комуникационни технологии (ИКТ) в законодателните дейности. Парламентите са интегрирали цифровите стратегии и целия цифров потенциал в парламентарните дейности. Цифровите технологии се използват масово в дейността на парламентите. До края на 2020 г. 65 \% от парламентарните комисии и 33 \% от парламентарните пленарни сесии са проведени в онлайн или хибриден формат. През последните две години в дейността на парламентите се появява нов онлайн формат на работа. От началото на пандемията ИКТ се преврьщат в основен елемент от парламентарната дейност.

Пандемията Covid-19 ускорява значително процеса на модернизиране на парламентарните процедури. Институционалната култура започва да се променя чрез прилагането на актуализирани методи и иновативни системи. По време на пандемията, благодарение на дигитализация на парламентарните дейности, те стават по-прозрачни и започват да реагират по-ефективно на различните предизвикателства чрез иновативни и гъвкави методи. Цифровата трансформация на парламентите преминава през три етапа: етапът на изпълнение, когато парламентите създават нови форми на дейност; втората фаза включва подобряване на процеса с оглед разработването на нови методи на работа; на следващия етап се консолидират нови решения и подходи, за да се въведат иновативни методи на работа в ежедневните процедури на парламентарните дейности.

Прилагането на концепцията за модела на електронния парламент е ускорена чрез използването на нови технологии за засилване на парламентарното участие и осигуряване на по-голямо политическо приобщаване. Електронният парламент като нова форма на управление в информационното общество предвижда активното използване на интернет технологиите за насърчаване на парламентарните дейности и привличане на общественото внимание към функциите на парламента. Електронният парламент се определя като концепция за организиране на работа с помощта на нови технологии, знания и стандарти за осигуряване на взаимодействие, приобщаващо участие на хората и свободен достъп. 


\section{Павлина Лозанова. Електронни правителства...}

Електронният парламент е система за управление, основана на автоматизирани процеси в рамките на парламента, и цели повишаване на ефикасността на парламентарните дейности и участието на всеки отделен член на обществото.

Съвременните интернет технологии предоставят уникални възможности на публичните органи, включително на парламентите, бързо да оповестяват закони и решения, както и да поддържат свободния поток на информация и да отговарят на исканията на гражданите своевременно. Публикуването на информация на официалните уебсайтове и разпространението им чрез други средства за обществена комуникация допринасят за изграждането на доверие към законодателната власт. Свободният обмен на информация между гражданите, обществото и държавата е важен фактор за повишаване на прозрачността и укрепване на стабилността на институциите. Предаването на аудио и видео данни в непрекъснат режим (стрийминг) във формат на онлайн дискусии, проучвания, електронни петиции, онлайн консултации също е един от най-често използваните инструменти, който допринася за повишаване нивото на откритост и прозрачност.

В условията на сьвременната цифрова реалност масовото използване на цифрови технологии в областта на дипломатическата дейност открива нови възможности за развитие на координирани действия за преодоляване на политически, социални и икономически кризи от страна на обществото. Дигиталната дипломация активно се развива в два формата: официална дипломация на държавни органи и частна дипломация на най-висшите служители на държавата. Политиците и дипломатите активно използват възможностите на Twitter, Facebook, YouTube и Instagram да провеждат дискусии по определени въпроси на своите официални страници (профили) с участието на голяма международна публика, чиято позиция може да повлияе на мнението на масите, имайки предвид, че броят на активните интернет потребители непрекъснато расте (повече от $59 \%$ от населението в света активно използва интернет).

Към днешна дата един от проблеми в международните отношения е нарастването на киберзаплахите. Безпрецедентното използване на цифрови решения, инструменти и услуги в отговор на пандемията ускорява глобалния преход към цифровизация. Нарастващата необходимост от използването на информационни технологии в различни области изисква голямо внимание към осигуряването на 


\section{Годишник на ФХН, XXXII A}

информационна сигурност. Правителствените сървъри често са обект на кибератаки, защото са носители на ценна информация: правителствени документи, лични данни и т. н. От година на година броят на кибератаките срещу държавните сървъри се увеличава. Все по-често в медиите се появяват новини за хакване на социални мрежи, на лична кореспонденция, както и получаване на достьп до класифицирани данни. Следователно е важно да се гарантира национална и социална устойчивост на системите, да се увеличат инвестициите в киберсигурността, както и да се преразгледат и преосмислят стратегиите за киберсигурност.

В Армения през 2008 г. правителството одобрява Концепцията за развитие на информационните технологии, която също установява концептуални разпоредби и график за въвеждани на електронно управление. През 2010 г. правителството на Република Армения въвежда портала за електронно управление. Сайтьт предоставя редица електронни услуги. Въведена е и система за електронни обществени поръчки, включваща изпълнението на процеса на възлагане на обществени поръчки в електронна форма. Правителството предприема програма за въвеждане на електронна циркулация на документи в държавните органи. Съществува електронна система за държавна регистрация на юридически лица, с помощта на която днес е възможно да се регистрира бизнес, без да се посещава съответната агенцията, като се използва системата за онлайн регистрация. Въведена е система за електронно подаване на заявления за лицензиране и система за подаване на електронни заявления до Агенцията за интелектуална собственост.

В Азербайджан Националната стратегия за информационни и комуникационни технологии за развитие на Република Азербайджан (2003 - 2012) полага основите на процеса на формиране на електронното правителство. Порталът „Електронно правителство“ е въведен в експлоатация през 2012 г. и се използва за предоставяне на централизирани електронни услуги на гражданите във формат на „един прозорец“ от централните изпълнителни органи. Броят на потребителите на електронни услуги, предлагани от портала на електронното правителство динамично се увеличава. Министерството на комуникациите и технологиите прилага мерки за увеличаване на използването на електронни услуги от държавни служители и обществеността.

В България Стратегията за развитие на електронното правителство за 2014 - 2020 г. определя информационните и 


\section{Павлина Лозанова. Електронни правителства...}

комуникационните технологии като основен компонент на развитието на съвременното информационно общество. България предприема мерки за по-нататъшно развитие на електронното управление със стойности около средните стойности за ЕС. Като член на ЕС България изпълнява основните направления на стратегическите документи на Европейския съюз, както и инициативи, които определят общите принципи на развитие и рамката за дейността на страните членки. Тези документи включват Стратегията „Европа 2020“, „Програма в областта на цифровите технологии за Европа“, „План за действие за електронно управление на Европейската комисия за периода 2011 - 2015 г.“" и програмата „ИСА“ (Решения за оперативна съвместимост на европейските публични администрации). На национално ниво основните насоки на Стратегията „Европа 2020“ са включени в стратегически документи като „Национална публична администрация“ и „Стратегия за развитие на електронното управление в България за 2014 - 2020 г.“. Проектьт „Модернизация на съществуващи и създаване на нови системи за електронно управление с цел подобряване на информационната и комуникационна среда за предоставяне на обществени услуги на гражданите и бизнеса“" е насочен към разширяване на електронното управление и повишаване на доверието на гражданите и бизнеса в системата на публичната администрация.

В Грузия електронното управление е неразделна част от реформите на публичната администрация, което позволява на страната да се превърне в една от най-динамично развиващите се в областта на управлението на информационните и комуникационните технологии. Като част от текущите реформи правителството на Грузия предприема мерки за създаване на информационни системи, прехвърляне на вътрешни информационни ресурси в електронен формат, автоматизиране на информационните потоци, създаване на центрове за обработка на данни, установяване на връзки между институции и регионални служби. Основните направления за прилагането на принципите на електронното управление на национално равнище са определени в документа „Цифрова Грузия“, както и в Стратегията за реформа в системата на публична администрация и плана за действие за периода 2015 - 2020 г. Същността на развитието на електронното управление в Грузия е да се гарантира ефективното прилагане на системата „единен прозорец“, като се изгради развита инфраструктура за ефективно институционално сътрудничество и участие на квалифицирано гражданско общество и частния сектор в областта на иновациите и развитието на електронните 


\section{Годишник на ФХH, XXXII A}

услуги. Цялостната концепция на стратегията за електронна Грузия е да осигури конкурентна и иновативна бизнес среда с най-добрите практики в областта на развитието на ИКТ.

В Молдова през 2011 г. правителството одобрява Стратегическата програма за технологична модернизация на управлението (електронна трансформация) с Резолюция № 710 от 20. 09. 2011 г., чиято цел е модернизиране на обществените услуги чрез цифровизация и реорганизация на оперативните процеси. През май 2012 г. правителството на Република Молдова стартира единен портал за обществени услуги - електронен каталог на услугите, предоставяни на гражданите и бизнеса. Платформата има две основни функции - обмен на информация и електронно взаимодействие между правителството и гражданите на Република Молдова. Освен това портальт позволява да се организира търсене по различни критерии и да се взаимодейства с модератора чрез формуляра за обратна връзка. Благодарение на стартирането на портала е постигната една от основните цели - да се предоставя коректна, достъпна и пълна информация за обществените услуги, предоставяни в Република Молдова.

В Румъния портальт за електронно правителство стартира през 2003 г. През 2010 г. се поставя началото на проект „Платформа за интегриране на услугите на електронното управление на Румъния“. През 2015 г. е приета Националната стратегия за програмата в областта на цифровите технологии за Румъния до 2020 г., въз основа на целите на документа на политиката на ЕС за икономическо развитие за следващите 10 години „Европа 2020“ и „Програма в областта на цифровите технологии за Европа за периода 2014-2020 г.“. През юни 2015 г. е създаден Органът за онлайн услуги и дизайн, който докладва директно на министър-председателя и наблюдава изпълнението на проекти за електронно управление.

В Русия основните направления на развитие на електронното управление се определят в съответствие с държавната програма на Руската федерация „Информационно общество (2011 - 2020)“ и Концепцията за разработване на механизми за предоставяне на държавни и общински услуги в електронна форма, одобрена на 25 декември 2013 г. от правителството на Руската федерация. Дельт на руските граждани, използващи механизма за получаване на държавни и общински услуги в електронна форма, надвишава 35\%. Към 1 октомври 2015 г. над 17 милиона руски граждани са регистрирани за получаване на обществени услуги в електронна форма - $22 \%$ от икономически активното население 
и $11,6 \%$ от населението на страната (през 2010 г. - $0,15 \%$ от населението, през 2012 г. - 1,8\%). Само през август 2015 г. броят на посещенията в единния портал на обществените услуги надхвърля 8 милиона.

В Сърбия работата по реализацията на концепцията за електронно управление започва през 2009 г. с изпълнението на проект на Министерството на далекосъобщенията и информационното общество на Сърбия. Предприемат се мерки по Стратегията за развитие на електронното правителство, както и по Стратегията за развитие на информационното общество до 2020 г. Дирекцията за електронно управление в Сърбия в рамките на своята компетентност извършва работа по организирането на проекти в областта на електронното управление в тясно сътрудничество с други институции и заинтересовани страни. Дирекцията се състои от два отдела - за стандартизация и развитие и за изпълнение на проекти. Задачата на Дирекцията на електронното управление е да гарантира предоставянето на електронни обществени услуги на населението на принципа „един прозорец“. Портальт за електронни услуги „електронно управление“ обединява услуги и информация от повече от 50 правителствени агенции, включително общински органи, и предоставя повече от 500 услуги.

През последните 15 години в Турция са осъществени важни дейности в областта на укрепването на електронното управление. Създадена е солидна инфраструктура на електронното управление, извършена е необходимата административна и техническа работа за широкото използване на системата за електронно управление от всички граждани. На 27 февруари 2003 г. с Постановление № 2003/12 на министър-председателя е одобрен Планът за изпълнение на „Турски проект за електронно преобразуване“, чрез който се провеждат реформи в областта на прилагането на ИКТ в различни отрасли. Освен това е одобрена стратегията за изграждане на информационното общество и съответния план за действие за периода 2015 - 2018 г., която предвижда осем етапа в подкрепа на икономическия растеж и заетостта. Стратегията се основава на пет основни компонента: показатели за развитието на информационното общество в Турция и настоящите нужди, основните предизвикателства пред Турция и бъдещите перспективи, разработването на национални, тематични и регионални стратегии, както и основните направления за прилагането на международните инструменти, включително „Програмата в областта на цифровите технологии за Европа““ на Европейския съюз. 


\section{Годишник на ФХH, XXXII A}

Министерството на транспорта, морското дело и съобщенията на Турция работи по изготвянето на „Стратегия и план за действие за развитие на електронното правителство за периода 2015 - 2019 г.“. Тази работа се извършва в две направления: (1) разработването на „Стратегия за развитие на електронното правителство и план за действие за 2015 2019 г.“; и 2) наблюдение на изпълнението на целите и референтните показатели на плана за действие. Прилагането на всеобхватни мерки за по-нататьшно развитие на електронното управление включва участието на правителството, частния сектор, гражданското общество и академичните среди. В процеса на формиране на информационното общество в Турция специална роля изиграва приемането на „Лисабонската стратегия“ и „Плана за действие за електронна Европа“.

В Украйна въвеждането на електронно управление е фактор за европейска интеграция, който осигурява ефективен тласък за хармонизиране на взаимодействието на властите с гражданите, публичните организации, бизнеса и други органи в съответствие с изискванията и стандартите на Европейския съюз. Тази сфера е регулирана от повече от 10 закона в Украйна, повече от 30 резолюции и 20 заповеди на Кабинета на министрите на Украйна. Една от основните задачи на Концепцията за развитие на електронното управление в Украйна $(2010$ г.) е организирането на предоставянето на услуги на гражданите и стопанските субекти в електронна форма, като се използват интернет и други средства, предимно на принципа „единен прозорец“. За първи път определението на термина „електронна услуга““ е представено в Стратегията за развитие на информационното общество в Украйна (2013 г.). Законът на Украйна „За административните услуги“ (2012 г.) установява възможност за подаване на документи за получаване на държавна услуга с помощта на далекосъобщения. Заповед на кабинета на министрите на Украйна (2014 г.) определя 52 административни услуги, които до края на 2014 г. следва да се предоставят само чрез центровете за административни услуги. През 2014 г. в Украйна е създаден национален портал за свободен достьп до данни. Създаването на правителствения уебсайт „Гражданско общество и власт“ се превръща в инструмент за провеждане на електронни консултации с обществеността.

Формирането на електронно управление обаче може да има и отрицателни последици. Без значение колко удобна и ефективна е системата, ако не осигурява надеждна защита на личните данни, тогава тя ще се изправи пред съпротива на потребителите, чието доверие ще бъде трудно да се възстанови. Защитата на личните данни може да бъде 


\section{Павлина Лозанова. Електронни правителства...}

гарантирана чрез технически, както и правни и организационни мерки. Макар че споделянето на информация е ключов компонент на електронното управление и предпоставка за насьрчаване на ИКТ приложенията, защитата на информацията е мярка, насочена към борба с изтичането на лични данни.

За да се актуализират основните принципи на електронното управление, е необходимо да се спазват редица условия, едно от които е да се повиши компютьрната грамотност на гражданите. Понастоящем не всички граждани използват активно информационни технологии, освен това не всички разполагат със средства за закупуване на подходящо оборудване. Разбира се, ако в информационното общество проблемът с достьпността на информационните технологии е без значение, то на етапа на формирането му значително предотвратява активното му въвеждане на електронно управление.

Към днешна дата разработването на голям брой ИТ проекти, включително проекти за развитие на национална система за електронно управление, присъстват във всички страни, тъй като все повече хора разбират, че ИТ проектите допринасят за гарантиране на ефикасността и прозрачността на процесите. Поради това за успешното изпълнение на ИТ проектите е необходимо да се предприемат правилно планирани мерки. Електронното правителство предполага глобално преструктуриране на формите на държавна дейност. В контекста на разработването на информационни и комуникационни технологии всички сфери на дейност на държавните органи в електронна форма са търсени от граждани и организации с различни форми на собственост.

Понастоящем съществуват всички инструменти за прилагането на електронното управление на практика, но формирането му е доста дълъг и ресурсно-интензивен процес. Въвеждането на електронно управление е насочено към това дейността на държавата да бъде прозрачна както за всеки гражданин, така и за обществото като цяло. Идеята на електронното управление е да въведе електронно управление на документи, което намалява бюрокрацията и ускорява процесите на вземане на решения, преврьща в електронна форма комуникацията на гражданите и бизнеса с властите, ще направи държавното и общинското управление по-прозрачно и ще доближи правителството до гражданите. Прилагането на тези принципи ще доведе до още по-голяма демократизация и ще допринесе за укрепването на гражданското общество. 


\section{Годииник на ФХH, XXXII A}

Страните от Черноморския регион са постигнали осезаеми резултати в интегрирането на програми в електронното управление. Предоставянето на обществени услуги чрез електронен формат на управление свежда до минимум ограниченията на времето и разстоянието и същевременно осигурява качествено нова форма на управление. Основните цели на електронното управление са постигането на максимална прозрачност на всички обществени структури, като се даде възможност и на гражданите да контролират процесите на изпълнение на политически решения на всички равнища.

\section{ИЗПОЛЗВАНА ЛИТЕРАТУРА}

Dobrev, Getsova 2005: Dobrev B., E. Getsova. Patevoditel za elektronno pravitelstvo. Sofia: International University [Добрев Б., Е. Гецова. Пьтеводител за електронно правителство. София: International University].

Kamenova, Popova 2003: Kamenova, N., M. Popova. Elektronno pravitelstvo sashtnost i nasoki na razvitie. // Publichna administratsiya [Каменова, Н., М. Попова. Електронното правителство - същност и насоки на развитие. // Публична администрация].

Mihaleva 2009: Mihaleva, S. Kontseptsiyata „Elektronno pravitelstvo” v konteksta na elektronnoto upravlenie [Михалева, С. Концепцията „Електронно Правителство” в контекста на електронното управление] $<$ https://ejournal.vfu.bg/en/pdfs/Svetla_Mihaleva-Koncepciata_Elektronno_ pravitelstvo'_v_kontektsta_na_elektronnoto_upravlenie.pdf (status 12.08.2021)>.

Nedyalkova, Filipov, Bauman 2005: Nedyalkova, A., D. Filipov, Z. Bauman. Globalizam, regionalizam i antiglobalizam. Sofia: Albatros [Недялкова, A., Д. Филипов, 3. Бауман. Глобализъм, регионализъм и антиглобализъм. София: Албатрос]. 